\title{
PRINCIPLE OF REHABILITATION \& COMPLICATION PREVENTION AFTER MUSCULOSKELETAL TRAUMA
}

\author{
Pamudji Utomo ${ }^{1}$, Hillan Akbar ${ }^{2}$ \\ ${ }_{1}^{1}$ Orthopaedic Consultant, Spine Subdivision, Department of Orthopaedic and Traumatology Faculty of Medicine \\ Sebelas Maret University, Surakarta, Indonesia. \\ ${ }^{2}$ Resident of Orthopaedic \& Traumatology Faculty of Medicine Sebelas Maret University, Surakarta, Indonesia \\ Maret, Surakarta, Indonesia. \\ Email:pamudjiutomo@gmail.com
}

\begin{abstract}
Rehabilitation plays a major role to maximize outcome and prevent complications following musculoskeletal trauma and its interventions. It is reported in several studies that mortality risk in patients not receiving rehabilitation was higher compared with patients who received one. The key principles include adequate pain management, antiinfection measures, early ambulation and physical therapy, establishing proper milestones and goals, wellcommunicated multi-disciplinary approach, and the establishment of standardized and personalized treatment protocol. Early mobilization is supported, as long as wound healing has been taken into consideration. Holistic approach to ensure both physical and psychosocial well-being is recommended, along with special care for geriatric and paediatric populations. Furthermore, alternative medicines such as acupuncture and meditation are currently gaining popularity and subsequently advocated as adjunct therapies.
\end{abstract}

Keywords: Rehabilitation, Complication, Musculoskeletal

\section{BACKGROUND}

Rehabilitation plays a major role to maximize outcome following musculoskeletal trauma and its interventions. Even what deemed as 'most successful' surgical procedures may develop complications. These include motion loss, stiffness, re-injury, joint instability, infection, along with many others.

Ireland et al. reported a $60 \%$ mortality risk reduction at 3 months and $40 \%$ at 1 year after hospital discharge in patients who received hospital-based rehabilitation compared with no rehabilitation ${ }^{1}$. Similarly, Tedesco et al. reported that the mortality risk in patients not receiving rehabilitation was more than twofold higher compared with patients who received hospital rehabilitation and it was $66 \%$ higher in those who received inpatient rehabilitation facilities (IRF), after adjustment for patient and intervention characteristics ${ }^{2}$.

Therefore, rehabilitation principles and strategies to minimize those complications should be well-understood and routinely used by the caregivers.

\section{REHABILITATION: KEY PRINCIPLES}

The essential key to treating complications is not allowing them to occur at all. Along with managing pain and preventing infection, one of the very first step is to induce motion and mobility as soon as possible. Early ambulation has been shown to reduce postoperative stiffness and motion loss at the knee joint ${ }^{3}$.

Traditional routines of rehabilitation following musculoskeletal trauma, including bed rest and prolonged immobilization, were detrimental to the patients' ability to return to pre-injury functional outcome levels ${ }^{4}$. Bed rest reduces the normal physiologic forces on skeletal muscle, causing muscle atrophy, which in severe cases can even lead to tetraplegia ${ }^{5}$. Prolonged immobilization is associated with numerous short-term risks including muscle 
atrophy, deep vein thrombosis, and joint stiffness, as well as long-term risks including persistent weakness, gait abnormalities and inability to return to previous activity levels ${ }^{6}$.

We believe that adjacent joints should be mobilized as soon as possible; however, in open fractures, motion of musculotendinous units over fracture surfaces would irritate the soft tissues and may decrease resistance to infection. We usually incorporate immobilization of adjacent joints with splints, braces, or foot attachments to external fixation systems to prevent contracture ${ }^{7}$.

Secondly, proper rehabilitation method should begin immediately, depending on the fracture and soft tissue stability ${ }^{7}$. This ensures patients are implementing appropriate physical therapy and receiving valid education regarding their condition and the things they both must carry out or steer clear of ${ }^{3}$. Physical therapy should include active and active-assisted exercises for joint mobilization as soon as soft tissue healing permits ${ }^{7}$.

The characteristics of physical therapy implemented are variable, depending on the type and severity of the injury, the patient's deficits, goals of therapy, resources, as well as the clinician's expertise. Generally, physical therapy has been proved to improve functional outcomes following most musculoskeletal injuries ${ }^{8}$.

Next, it is crucial for the rehabilitation team to establish proper milestones and goals, ensuring patients are not falling behind, becoming stiff, or in some cases moving too fast $^{3}$. A dedicated, multi-disciplinary team approach consisting of orthopaedic surgeon, physical therapist, occupational therapist, strength and conditioning specialist, nursing team, pain services, nutritionist, and psychologist is crucial ${ }^{9,10,11}$. Physical, emotional, and psychological well-being are every bit as essential. All members of the team should be included in treatment planning, and effective communication among those members is invaluable ${ }^{3}$.

Lastly, developing a proper treatment protocol is vital for successful outcome. The treatment protocol serves as a guideline for the team to recognize what is or should be happening and when it is expected to occur ${ }^{3}$. This provides the team with better preparation and minimizes risks of medical errors. Not only standardized, the protocol should also be personalized based on patient's capabilities and level of cooperation ${ }^{5}$.

In terms of post-operative management, Fan and Arraf $^{12}$ divided it into three phases:

1. In the first phase, immediately after surgery, emphasis is on pain control, mobilization, prevention, and early recognition of complications.

2. In the second phase, after hospitalization, attention is centred upon integration into the social environment and mobilization.

3. The final phase concludes treatment and returns the patient to his/her preoperative capabilities including work, education, and leisure activities.

\section{MANAGING PAIN}

In addition to being an unpleasant experience, poorly controlled pain may have inimical physiological consequences for the patient leading to increased morbidity and poor recovery ${ }^{12}$. Pain can also be used as a predictor for physical disability ${ }^{13,14}$. 
Table 1. Best Practice Recommendations for Alleviation of Acute Pain After Musculoskeletal Injury $^{16}$

\begin{tabular}{|c|c|}
\hline Category & Recommendations \\
\hline Pain medication strategies & 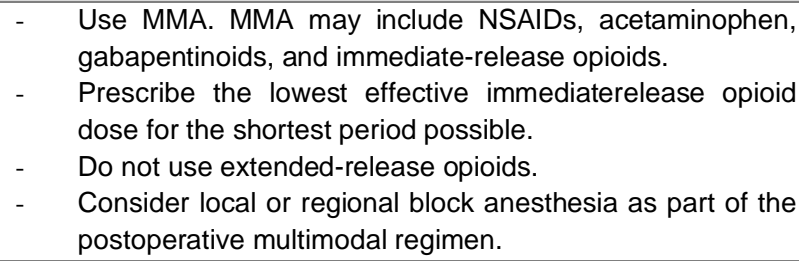 \\
\hline Cognitive strategies & $\begin{array}{l}\text { - Discuss alleviation of pain, expected recovery course, and } \\
\text { patient experience at all encounters. } \\
\text { - Connect patients with pain that is greater or more persistent } \\
\text { than expected and patients with substantial symptoms of } \\
\text { depression, anxiety, or posttraumatic stress or less } \\
\text { effective coping strategies (greater catastrophic thinking } \\
\text { and lower self-efficacy) to psychosocial interventions and } \\
\text { resources. } \\
\text { Consider using strategies for optimal mindset such as } \\
\text { aromatherapy, music therapy, or approaches based on } \\
\text { cognitive behavioral therapy. }\end{array}$ \\
\hline Physical strategies & $\begin{array}{ll}\text { - } & \text { Use immobilization, ice, and elevation appropriately. } \\
\text { - } & \text { Consider the use of TENS units. } \\
\text { - } & \text { Consider the use of cryotherapy units }\end{array}$ \\
\hline $\begin{array}{l}\text { Strategies for patients on longterm opioids at } \\
\text { presentation }\end{array}$ & $\begin{array}{l}\text { - Use balanced physical, cognitive, and pharmaceutical } \\
\text { strategy for alleviation of pain } \\
\text { - Ensure that there is only } 1 \text { prescriber by coordinating with } \\
\text { APS (or addiction medicine or psychiatry depending on } \\
\text { resources) when inpatient and the patient's prescriber } \\
\text { when outpatient }\end{array}$ \\
\hline Pain assessment strategies & $\begin{array}{l}\text { - Assess pain and sedation regularly for inpatients with short } \\
\text { validated tools. }\end{array}$ \\
\hline System strategies & $\begin{array}{l}\text { - Query the state and relevant regional PDMP before } \\
\text { prescribing opioids. } \\
\text { - Develop and support the implementation of clinical decision } \\
\text { support for opioid prescribing in the electronic medical } \\
\text { record. } \\
\text { - Support opioid education efforts for prescribers and } \\
\text { patients. } \\
\text { - Implement pain medication prescribing strategy or policy. }\end{array}$ \\
\hline
\end{tabular}

*In conjunction with pain medication recommendations and individualized per treating physician discretion according to patient characteristics, local practice preferences, and state law.

High levels of general anxiety immediately after injury significantly predicted the development of chronic pain, along with pre-existing factors, such as diabetes, anxiety disorders, injury severity, and surgical interventions ${ }^{15}$. Other predictors that are believed to be related are lower socioeconomic status, smoking, IV drug use, and increasing age. Evidence-based analgesic regimens are required as part of protocols to improve function and compliance with rehabilitation, and to decrease the economic burden of disability ${ }^{13}$.

Recommendation for acute pain management following musculoskeletal injury is shown on Table $1^{16}$.

\section{Opioids}

Opioid analgesics are a cornerstone of treatment for moderate to severe 
postoperative pain. Opioids exert their analgesic effects in the central nervous system at the $\mu$-, $\mathrm{k}$-, and $\delta$-receptors ${ }^{12}$.

Despite its potency to adequately manage acute pain, opioids have been proven to cause a number of side effects including opioid-induced hyperalgesia, sedation, nausea, ileus and respiratory depression ${ }^{14}$. Furthermore, fear of causing addiction has been one of the major reasons that physicians avoid prescribing opioid analgesics ${ }^{17}$. Carnide et al. found that early opioid prescription following musculoskeletal injury was associated with prolonged work disability ${ }^{18}$. A randomized controlled trial carried by Chang et al. ${ }^{19}$ stated that there was no significant difference in acute extremity pain reduction between a non-opioid com- bination (acetaminophen and ibuprofen) and opioid combination groups.

Special considerations need to be taken in administrating opioids. For example, morphine should be avoided in patients with renal insufficiency because of the abundant toxic metabolites to be excreted. Therefore, hydromorphone (6-7 times as potent as morphine) or fentanyl (100 times as potent as morphine) which lack toxic metabolites are more suitable ${ }^{12}$. Codeine should not be used as a first line analgesic unless the patient has a favourable history with this drug. Oxycodone, like morphine, is commonly used as a sustained-release preparation for around-theclock dosing ${ }^{12}$.

\section{Non-opioids}

Acetaminophen is an effective analgesic and antipyretic, and is usually used for mild pain or combined with other analgesics for more severe ones. It has no antiinflammatory effect, and the total daily dose of acetaminophen for adults from all sources must not exceed $4 \mathrm{~g}$ to prevent liver toxicity ${ }^{12}$.

Nonsteroidal anti-inflammatory drugs (NSAIDs) given even as a single dose preoperatively can significantly decrease morphine requirements by up to $29 \%$ over 24 hours ${ }^{7,20}$. This results in lower incidence of opioid-induced adverse effects. NSAIDs are effective in minimizing pain associated with movement, thereby facilitating postoperative physiotherapy and minimizing postoperative physiological impairment. This is different with opioids which exert their effect predominantly on rest pain. The common side effects of NSAIDs are gastric bleeding and ulceration, bleeding from the operative site, nephrotoxicity, bronchospastic hypersensitivity reactions, and the suppression of heterotopic bone formation. They should be used with care in geriatric patients and avoided in patients with impaired renal function ${ }^{12}$.

Neuromodulating drugs, such as amitriptyline, gabapentin, and pregabalin have been explored for their analgesic effect in the setting of postoperative pain. These drugs may also have a place in the management of phantom pain following amputation ${ }^{12}$.

Unlike acute pain, chronic pain defined as persistent or recurrent pain lasting more than 3 months or beyond the normal tissue healing period - is a much more complex entity to manage and holistic approach is necessary ${ }^{21}$. 


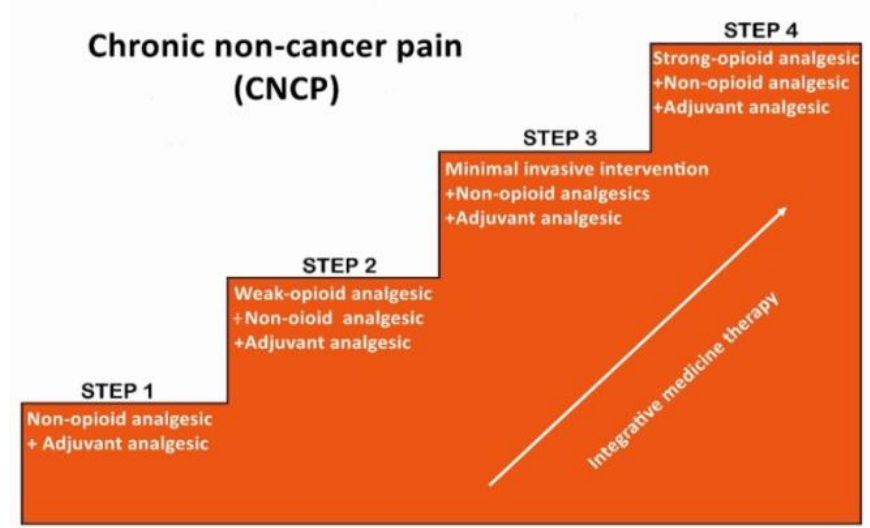

Figure 1. Modified Four-Steps WHO Analgesic Pain Ladder for CNCP22.

The three-steps WHO Analgesic Pain Ladder is typically used for chronic cancer pain (CCP). Its three steps are: Step 1 Non-opioid plus optional adjuvant analgesics for mild pain; Step 2 Weak opioid plus non-opioid and adjuvant analgesics for mild to moderate pain; Step 3 Strong opioid plus non-opioid and adjuvant analgesics for moderate to severe pain. It is advised to move up one step when there is persistent pain. In case of toxicity or severe adverse effects, providers are advised to either reduce medication doses or move down one step ${ }^{22}$. However, this protocol is not appropriate for chronic non cancer pain (CNCP) management, therefore it has been adapted into four-step ladder (Figure 1).

An integrative, conventional approach, such as acupuncture, yoga, massage relaxation techniques, healing touch, meditation, along with properly-carried out cognitive behavioural therapy is now preferred $^{22,23,24}$.

Table 2. Pain Medication Recommended Taper* Following a Major Musculoskeletal Injury Procedure (eg, Operative Fixation of Long Bone or Complex Joint Fracture, Extensive Soft Tissue Injury or Surgery, etc. $)^{16}$

\begin{tabular}{|c|c|c|}
\hline Status & Opioid & Nonopioid \\
\hline Inpatient & $\begin{array}{l}\text { - } \text { Oxycodone/acetaminophen } \\
-5 \mathrm{mg} / 325 \mathrm{mg} 1 \text { tab po q } 4 \mathrm{~h} \text { PRN } \\
\text { moderate pain } \\
-5 \mathrm{mg} / 325 \mathrm{mg} 2 \text { tabs po q } 6 \mathrm{~h} \text { PRN severe } \\
\text { pain (hold next acetaminophen scheduled } \\
\text { dose) } \\
\text { - Hydromorphone } 1 \mathrm{mg} \text { IV q } 3 \mathrm{~h} \text { PRN for severe } \\
\text { breakthrough pain }\end{array}$ & $\begin{array}{l}\text { - Ketorolac } 15 \mathrm{mg} \text { IV q } 6 \mathrm{~h} \text { x } 5 \text { doses, followed by } \\
\text { ibuprofen } 600 \mathrm{mg} \text { po q } 8 \mathrm{~h} \\
\text { - } \text { Gabapentin } 100 \mathrm{mg} 1 \text { tab po TID } \\
\text { - Scheduled acetaminophen } 500 \mathrm{mg} \text { po q } 12 \mathrm{~h}\end{array}$ \\
\hline $\begin{array}{c}\text { Postdischarge } \\
\text { Week } 1 \text { (at discharge) }\end{array}$ & $\begin{array}{l}\text { - Oxycodone/acetaminophen } \\
\text { - } 5 \mathrm{mg} / 325 \mathrm{mg} 1 \mathrm{tab} \text { po q } 4 \mathrm{~h} \text { PRN } \\
\text { - } \quad \text { Dispense \#42 ( } 1 \text { time Rx, no refills) } \\
\text { - Hydrocodone/acetaminophen } \\
\text { - } 5 \mathrm{mg} / 325 \mathrm{mg} \text { or tramadol } 50 \mathrm{mg} \text { (only if } \\
\quad \text { necessary -3 Rx Max) }\end{array}$ & 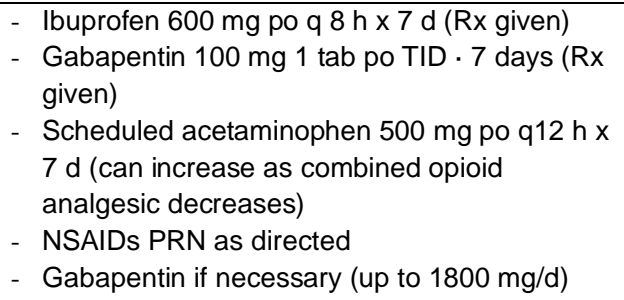 \\
\hline Week 2 & $\begin{array}{l}\text { - } 1 \text { tab po q } 4 \text { h PRN } \\
\text { Dispense \#42 }\end{array}$ & $\begin{array}{l}\text { - Scheduled acetaminophen } 500 \mathrm{mg} \text { po q12 h } \\
\text { (can increase as combined opioid analgesic } \\
\text { decreases }\end{array}$ \\
\hline
\end{tabular}




\begin{tabular}{|c|c|c|}
\hline Week 3 & $\begin{array}{l}\text { - } 1 \text { tab po q6 hours PRN } \\
\text { Dispense \#28 }\end{array}$ & $\begin{array}{l}\text { - Scheduled acetaminophen } 1000 \mathrm{mg} \text { po q12 } \mathrm{h} \\
\text { (can increase as combined opioid analgesic } \\
\text { decreases) }\end{array}$ \\
\hline Week 4 & $\begin{array}{l}\text { - } 1 \text { tab po q8 hours PRN } \\
\text { Dispense \#21 }\end{array}$ & $\begin{array}{l}\text { - Scheduled acetaminophen } 1000 \text { mg po q8 } \\
\text { hours (can increase as combined opioid } \\
\text { analgesic decreases) }\end{array}$ \\
\hline Weeks 5+ & & $\begin{array}{l}\text { - NSAIDs PRN as directed } \\
\text { - Acetaminophen PRN as directed } \\
\text { - Gabapentin if necessary (then wean) }\end{array}$ \\
\hline
\end{tabular}

Table 3. Pain Medication Recommended Taper* Following a Minor Musculoskeletal Injury Procedure (e.g., Operative Fixation of Small Bone or Simple Joint Fracture, Minimal Soft Tissue Injury or Surgery, etc.) $)^{16}$

\begin{tabular}{|c|c|c|}
\hline Status & Opioid & Nonopioid \\
\hline $\begin{array}{l}\text { Postdischarge } \\
\text { Week } 1\end{array}$ & $\begin{array}{l}\text { - Hydrocodone/acetaminophen } \\
\text { - } 5 \mathrm{mg} / 325 \mathrm{mg} \text { or tramadol } 50 \mathrm{mg} 1 \text { tab po q } \\
6 \mathrm{~h} \mathrm{PRN} \\
\text { - Dispense \#28 (1 time Rx, no refills) } \\
\\
\text { - Hydrocodone/acetaminophen } \\
\text { - } 5 \mathrm{mg} / 325 \mathrm{mg} \text { or tramadol } 50 \mathrm{mg} \text { (only if } \\
\text { necessary - } 2 \mathrm{Rx} \text { Max) }\end{array}$ & $\begin{array}{l}\text { - } \text { Ibuprofen } 600 \mathrm{mg} \text { po q } 8 \mathrm{~h} \times 7 \mathrm{~d} \text { (Rx given) } \\
\text { - Gabapentin } 100 \mathrm{mg} 1 \text { tab po TID x } 7 \mathrm{~d}(\mathrm{Rx} \\
\text { given) } \\
\text { - Scheduled acetaminophen } 1000 \mathrm{mg} \text { po q12 h } \\
\text { (can increase as combined opioid analgesic } \\
\text { decreases) } \\
\text { - NSAIDs PRN as directed } \\
\text { - Gabapentin if necessary (up to } 1800 \mathrm{mg} / \mathrm{d} \text { ) }\end{array}$ \\
\hline Week 2 & $\begin{array}{l}\text { - } 1 \text { tab po q } 8 \text { h PRN } \\
\text { Dispense \#21 }\end{array}$ & $\begin{array}{l}\text { Scheduled acetaminophen } 1000 \mathrm{mg} \text { po q8 } \\
\text { hours (can increase as } \\
\text { combined opioid analgesic decreases }\end{array}$ \\
\hline Week 3 & $\begin{array}{l}\text { - } 1 \text { tab po q12 h PRN } \\
\text { Dispense \#14 }\end{array}$ & $\begin{array}{l}\text { - Scheduled acetaminophen } 1000 \mathrm{mg} \text { po q8 } \\
\text { hours (can increase as } \\
\text { combined opioid analgesic decreases) }\end{array}$ \\
\hline Weeks 4+ & & $\begin{array}{l}\text { - NSAIDs PRN as directed Acetaminophen PRN } \\
\text { as directed }\end{array}$ \\
\hline \multicolumn{3}{|c|}{$\begin{array}{l}\text { Dosage and duration can be less if tolerated. } \\
\text { *In conjunction with other best practice recommendations and individualized per treating physician discretion according to patient } \\
\text { characteristics, local practice preferences, and state law. }\end{array}$} \\
\hline
\end{tabular}

\section{Table 4. Pain Medication Recommended Taper* Following a Nonoperative Musculoskeletal Injury (e.g., Closed Management of Injury, Laceration Repair, etc. ${ }^{16}$}

\begin{tabular}{|c|c|c|}
\hline Injury Category & Opioid & Nonopioid \\
\hline $\begin{array}{l}\text { Minor injury (eg, small } \\
\text { bone fracture, sprain, } \\
\text { laceration, etc.) }\end{array}$ & $\begin{array}{l}\text { - Tramadol } 50 \mathrm{mg} \text { (only if necessary } 2 \mathrm{Rx} \text { Max) } \\
1 \text { tab po q } 6 \mathrm{~h} \text { PRN } \\
\text { Dispense \#20, then \#10 }\end{array}$ & $\begin{array}{l}\text { NSAIDs PRN as directed } \\
\text { - Scheduled acetaminophen } 1000 \mathrm{mg} \text { po q8 } \\
\text { hours, then PRN as directed }\end{array}$ \\
\hline $\begin{array}{l}\text { Major injury (eg, large } \\
\text { bone fracture, rupture, } \\
\text { etc.) }\end{array}$ & $\begin{array}{l}\text { - Hydrocodone/acetaminophen } \\
5 \mathrm{mg} / 325 \mathrm{mg} \text { or tramadol } 50 \mathrm{mg} \\
\text { (only if necessary-2 Rx Max) } \\
1 \text { tab po q } 6 \text { h PRN } \\
\text { Dispense \#20, then \#10 }\end{array}$ & $\begin{array}{l}\text { - NSAIDs PRN as directed } \\
\text { - Scheduled acetaminophen } 1000 \mathrm{mg} \text { po q12 h, } \\
\text { then PRN as directed }\end{array}$ \\
\hline \multicolumn{3}{|c|}{$\begin{array}{l}\text { Dosage and duration can be less if tolerated. } \\
\text { *In conjunction with other best practice recommendations and individualized per treating physician discretion according to patient } \\
\text { characteristics, local practice preferences, and } \\
\text { state law }\end{array}$} \\
\hline
\end{tabular}

Recommendations for pain medication following major, minor, and nonoperative musculoskeletal injury are shown on Table 2, Table 3, and Table 4 respectively ${ }^{16}$. It is also recommended to implement physical modalities, such as transcutaneous electrical simulation (TENS) as an adjunct to other immediate postinjury or postoperative pain treatments (strong recommendation, lowquality evidence $)^{16}$. TENS attempts to modulate pain through delivery of low-voltage electric currents over the skin from a small 
portable device. The stimulation of large diameter peripheral afferent nerve fibres is believed to reduce pain by activating opioid receptors through an endogenous descending inhibitory pathway ${ }^{25}$. The contraindications to the use of TENS include the presence of a pacemaker or implanted defibrillator, broken skin at the site of application, or significant lymphedema ${ }^{16}$.

Cryotherapy (conditional recommendation, low-quality evidence) is another option that can be used as an adjunct $^{16}$. An external cold source is applied to decrease tissue temperature. It is believed that cryotherapy may help decrease: tissue oedema and microvascular permeability, delivery of inflammatory mediators, blood flow (via vasoconstriction), tissue metabolic demand, and subsequent hypoxic injury. It may also increase threshold of painful stimuli and the tolerance to pain ${ }^{16}$.

\section{PREVENTING INFECTION}

Infections occur in $5 \%$ to $10 \%$ of open femoral and tibial fractures fixed with intramedullary nailing, and pin track infections occur in $0.5 \%$ to $42 \%$ treated with external fixation. Orthopaedic surgical site infections have been reported to prolong total hospital stays by an average of 2 weeks, approximately double rehospitalization rates, and increase health care costs by more than $300 \%$. In addition, patients with orthopaedic surgical site infections have substantially greater physical limitations and reductions in their healthrelated quality of life. Thus, it is important to prevent these infections when possible and to administer prompt and appropriate treatment when they occur ${ }^{7}$.
Measurement of C-reactive protein levels has been reported to be valuable in the diagnosis of infection after internal fixation of fractures. In all patients studied, C-reactive protein levels increased after surgery, peaking on the second postoperative day, after which levels decreased. In those without infection, Creactive protein levels continued to decrease but in those with infections a secondary elevation in C-reactive protein levels was noted beginning on the fourth day after surgery. A C-reactive protein value of greater than or equal to $96 \mathrm{mg} / \mathrm{L}$ on the fourth day after surgery was found to be predictive of infection ${ }^{7}$.

\section{Irrigation and debridement}

Irrigation and debridement to remove gross contamination and all devitalized tissues is often the first step in the prevention of infection and proliferation of microbials after injury ${ }^{26}$. Debridement must be performed by an experienced team (ortho-plastic approach preferred) as early as possible and adequate quantity of fluid must be ensured in lavage procedure. Low pressure pulsatile lavage with normal saline is preferred as it has less harmful effects on tissues ${ }^{27}$. The practice of obtaining routine cultures from the wound either pre- or post- debridement is no longer advocated ${ }^{28}$.

\section{Wound care}

To allow surgical wounds to dry as quickly as possible, they are covered with sterile, absorbent gauze that allows for air circulation or a composite hydrophilic wound dressing. If used, suction drainage remains in place for about 24 hours if there are routine amounts of exudation. For larger volumes of exudate, as in pelvic or hip fractures, 48 hours may be required. Articular fractures are a special case and should be drained for no 
more that $8-12$ hours. Beyond these times, the risk of infection is increased ${ }^{12}$.

If the wounds have bled extensively, the first change of dressings takes place 24 hours after surgery; otherwise they can remain in place for 48 hours and hydrophilic dressings may be left for longer. Thereafter, the dressings are changed daily to prevent the formation of a moist environment. Such changes are carried out under strict hygienic conditions, with chlorhexidine solutions with alcohol recommended as disinfectant. As soon as bleeding or secretion ceases, the wound is left uncovered. Even with sutures in place, the patient can bathe or undergo hydrotherapy if the wound is temporarily protected by a watertight dressing (e.g. OpSite film, Tegaderm $)^{12}$.

Open wounds should be covered with an occlusive dressing (possibly including antibiotic beads to produce an antibiotic pouch) and left undisturbed, to reduce the risk of nosocomial infection, until the patient returns to the operating room. Alternatively, a negative-pressure dressing can be used. Early clinical experience is good and these new dressings are currently being evaluated with prospective randomized controlled trials ${ }^{12}$.

\section{Antibiotic Administration}

Given the very high incidence of infection, administration of antibiotics once the limb is properly splinted, bleeding has been controlled, and the wound is covered with a wet saline dressing, has become routine ${ }^{26}$.

Commonly recommended regimens include first or second-generation cephalosporins, penicillin, or, if the patient has an allergy to such agents, clindamycin ${ }^{29,30}$. As of today, cephalosporin is given for minor wounds; while for major wounds, severe crush injuries, or agricultural injuries, penicillin, gram negative coverage-with Gentamycin, and anaerobic coverage-with Metronidazole, can be added ${ }^{29}$.

A relatively recent concern has been the frequency of methicillin-resistant Staphylococcus aureus (MRSA) infections in trauma patients; the reported rate of MRSA infections (11\%) in trauma patients is nearly double that reported in general orthopaedic patients ( $4 \%$ to $5.6 \%$ ). One study found that MRSA carrier status at the time of admission, hip fracture, and advancing age (with an almost $2 \%$ increase in relative risk per year) were associated with higher rates of infection in orthopaedic trauma patients. These infections should be treated aggressively with repeat surgical debridement and appropriate antibiotic coverage (usually intravenous) ${ }^{7}$.

The algorithm for antibiotic use in open fracture (based on Gustilo-Anderson classification) can be found in Figure $2^{31}$. Type I or II fractures necessitate gram positive coverage while Type III fractures require the addition of gram-negative coverage with aminoglycoside. Similar efficacy is found in ceftriaxone as compared to cefazolin plus gentamicin in Type III fractures. Fluoroquinolones may be detrimental to fracture healing and may result in higher infection rates in Type III fractures. 


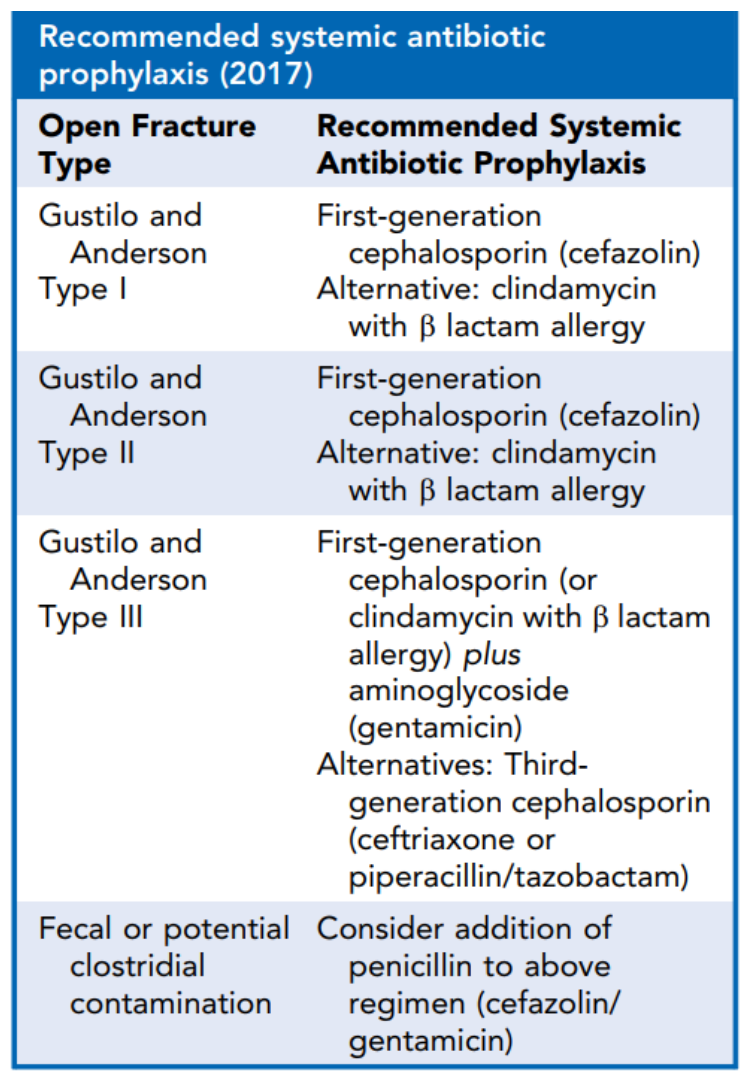

Figure 2. The algorithm for antibiotic use in open fractures ${ }^{31}$.

The timing is also important, as it is demonstrated by lower infection rate $(4.7 \%)$ if antibiotics are given within 3 hours after the injury, compared with $7.4 \%$ if antibiotics were delayed for greater than 3 hours ${ }^{32-34}$. The prolonged use of antibiotics is not indicated and will lead to the development of resistant organisms ${ }^{35}$.

When infection occurs in the presence of a skeletal fixation device (plate, nail, external fixator), there is a trade-off between bony stability and foreign body response. Stability is necessary to eliminate the infection, but organisms may remain adherent to the orthopaedic implant, resulting in a persistent infection. If an implant is not needed to maintain bony stability, it should be removed. Implants needed for stability should be retained until bony stability occurs, or they should be replaced by another form of fixation (e.g., removing a plate and replacing it with an external fixator $)^{7}$.

Other concern is the development of gas gangrene. The term gas gangrene implies an infection with the Clostridium species of anaerobic bacteria, but many necrotizing soft tissue infections are caused by mixed aerobic and anaerobic gram-negative and gram-positive bacteria. Clostridium can be cultured from approximately $30 \%$ of deep infections, but only a few progresses to myonecrosis. Clostridium species, most commonly C. perfringens, C. novyi, and $C$. septicum, cause the most dramatic infections and are the deadliest, with mortality rates of $40 \%$ reported. Although gas gangrene 
usually is associated with open fractures or other severe soft tissue trauma, it can occur after surgery or with no antecedent trauma ${ }^{7}$. There remains lack of consensus about the role of extended spectrum gram-negative and Clostridial coverage in antibiotic prophylaxis recommended regimen after open fracture ${ }^{26}$.

\section{PROTECTION, SUPPORT, AND EARLY AMBULATION}

Many surgeons have their own preferred regimens but the guidelines shown in Table $5^{12}$ are widely applicable. Removable plaster bandages or splints, if they are used after procedure, must not lead to malpositioning nor inhibit early postoperative mobilization and physical therapy. Splints on the forearm and hand are placed in the position of safety to prevent contracture of the muscles and joints. In all patients with lower limb fractures, it is essential to prevent pes equinus deformity of the ankle and foot by using appropriate splints. In patients with a tendency toward pes equinus position, a $\mathrm{U}$ splint is adapted to fit the lower limb. Splints with hinges that allow limited mobility are helpful either in gradual mobilization after an articular fracture, or if there have been associated ligamentous lesions ${ }^{12 .}$

Early mobilization is important to reduce the risk of thrombosis. Articular fractures require early mobilization and a continuous passive motion machine can be applied as soon as the wound condition allows ${ }^{12}$

Patients who have had an operation on the upper extremity should get up on the day of their surgery. If the lower extremity has been operated upon, ambulation is minimized until soft- tissue swelling has disappeared and the wound shows no signs of inflammation. Early mobilization should not interfere with wound healing ${ }^{12}$.

\section{REGAINING FUNCTION}

The primary goal of rehabilitation is to regain mobility and function. Stiffness is the most common clinical problem after trauma, particularly in upper extremity. This deficit in range is usually well tolerated; however, in contrast, loss of flexion significantly affects function because the hand is unable to reach the head and mouth ${ }^{36}$.

A careful history is essential to establish an accurate diagnosis, as well as to gather sufficient information about an individual to allow a safe, effective and efficient physical examination ${ }^{37}$. Several aspects that need to be taken into considerations when taking history include: 1) Age and hand dominance; 2) History of injury, subsequent management and complications; 3) Degree, duration and progression of stiffness; 4) Impact of stiffness on activities of daily living; 5) Pain, nature and behaviour; 6) Neurological symptoms; and 7) Locking or mechanical symptoms.

Initial observation includes the appearance of deformity, muscle wastage, previous scars, prominent metalwork, along with oedema, colour changes, and trophic changes. Palpate bony anatomy to identify any abnormalities. Next, range of motion should be evaluated by passive and active flexion, extension, rotation, pronation, and supination. Accessory joint motion - defined as the 
movements that cannot perform actively but which can be performed on that person by an external force - should also be evaluated ${ }^{37}$.

Particular attention should be paid to neurovascular deficits. Assessment should include the presence of allodynia, hyperpathia, changes in pain pressure thresholds and the presence of cold hyperalgesia. Changes in pain pressure threshold may indicate a central pain component, whereas cold hyperalgesia may indicate an autonomic component ${ }^{37}$. Sensory testing should consist of stereognosis testing and two-point discrimination testing ${ }^{38}$.

Imaging of the patient should include plain films including at least anteroposterior and lateral views ${ }^{36}$. This can help clarify bony causes of motion restriction (including osteophytes, loose bodies, heterotopic ossification, non- or malunions, erosions) and inform the therapist regarding the likely outcome of conservative management ${ }^{37}$. Nerve conduction study, performed in the presence of neurological dysfunction, should also be reviewed to inform decision-making regarding treatment and prognosis $^{37}$.

Physical therapies that can be implemented to regain function include active exercises, passive mobilization, and continuous passive motion ${ }^{37}$.

Active exercises are used by the majority of therapists, aiming to reduce the effect of immobilization on the capsule, ligaments, muscles and osteochondral tissues ${ }^{40}$. It is initiated with active-assisted, and then progressed to active movements without assistance as soon as comfort allows, with exercises performed in a protected range as defined by the nature of surgery or injury ${ }^{37}$. They must be performed frequently throughout the day and involve all planes of muscle and joint motion.

Passive mobilizations is performed using mobilizations with movement (MWM) methods, where the therapist identifies a limited or painful motion, then the patient actively repeats the motion at the same time as the therapist performs a gliding technique to the joint ${ }^{7,41}$. This technique has been shown to have a direct effect on pain pressure thresholds, to improve range of motion during neurodynamic testing and to improve painfree grip. In terms of elbow injury, MWMs may also be a useful adjunct in treating the painful elbow at risk of developing stiffness, in situations where direct mobilization of the elbow is not appropriate (i.e. immediately after injury) ${ }^{37}$. Despite promising results, the follow-up in these studies is extremely lacking, and further trials are needed $^{37}$.

Continuous passive motion (CPM) has been commended to prevent tissue oedema practically by squeezing fluid away from the joint and periarticular tissues - thus minimizing the cascade of events leading to soft tissue contractures. It is advised to be performed as soon as clinically possible for long periods of time through the largest possible safe arc of motion. Although, theoretically, CPM would appear to be beneficial, there is little evidence to recommend its use $\mathrm{u}^{37}$.

Stretching, both static and dynamic, is also a common intervention performed during rehabilitation. Stretching is prescribed to increase muscle length and ROM, or to align collagen fibres during healing muscle ${ }^{42}$. Despite positive outcomes, it is difficult to isolate the effectiveness 
of the stretching component of the total treatment plan.

Better results with conservative management are achieved when interventions are initiated at an early stage because the first 6 months after injury represents the critical rehabilitation period ${ }^{37}$. Giannicola et al. ${ }^{39}$ report that $70 \%$ of patients recovered functional range between 3 months and 6 months post injury, with recovery of flexion being slowest to improve. Thereafter, improvement occurred at a slower rate, until 12 months post injury, when $80 \%$ of patients had recovered functional range.

Following the assessment, time should be available to formulate a treatment plan with the patient, with agreed goals and appropriate realistic timescales for any change to occur ${ }^{36}$.

\section{IMPROVING STRENGTH}

Strengthening is subsidiary in terms of rehabilitation and it should not be formally endorsed until sufficient range of motion and adequate tissue healing are gained.

Resistance training (RT) is a useful tool in the rehabilitation of a variety of musculoskeletal conditions, especially those where loss of muscular strength and functional ability is evident ${ }^{43}$. High-intensity RT does not appear feasible post ACL reconstruction surgery because knee-joint stressed should be avoided, whereas the integrity of the new graft should not be jeopardized. However, high-intensity RT shows clear beneficial effects when commenced very shortly after hip replacement surgery ${ }^{43}$.

Theoretically, elderlies have reduced capacity to adapt to a given exercise stimulus; however, the positive effects of RT in a rehabilitation context are evident even in patients of advanced age. Younger patients may likely respond more favourably to $\mathrm{RT}$ than their older counterparts, but it can still be used across all ages as an effective therapeutic tool ${ }^{43}$. Periodized RT will allow patients to gradually improve their maximal strength and become accustomed to heavier loads. This approach has been shown to be effective at improving muscular strength and functional ability and reducing patient symptoms ${ }^{44}$.

In another study ${ }^{45}$, it is stated that a home strengthening exercise program is more effective than delayed, "wait and see" return of strength. The benefits of adding eccentric or concentric strengthening and supervised progressive strength training vary in previous literatures ${ }^{45,46}$.

Once range of motion and early strength recovery is achieved, more specialized rehabilitation can be instituted to help a patient achieve their functional goals.

\section{ENSURING PSYCHOLOGICAL WELLBEING}

A notable portion of trauma patients have substantial symptoms of anxiety, depression, and post-traumatic stress disorder months after injury ${ }^{16}$.

Patients with psychiatric illnesses are negatively impacted by musculoskeletal trauma irrespective of injury severity, require longer lengths of stay and utilize more hospital resources ${ }^{47-50}$. Studies by Beaipre et $\mathrm{al}^{51}$ and Morghen et $\mathrm{a}^{52}$ found that patients suffering from moderate to severe depressive symptoms following hip fracture are less likely to be able to walk independently, are more likely to be 
institutionalized, and have increased one-year mortality following fracture.

Psychiatric illness is commonly underreported or unrecorded, delaying clinicians' ability to provide patients with the necessary psychosocial supports ${ }^{47,48}$. Early identification of psychiatric illness and risk stratification of is recommended to improve postoperative recovery, particularly in 'poor' candidates. These include those who exhibit psychological distress, fear-avoidance behaviour, poor self-efficacy, and pessimistic personality traits ${ }^{53}$.

Psychological processes including patient expectations and beliefs are closely tied to the subjective experience of pain and interfere with physical recovery ${ }^{49,50}$. The Somatic Preoccupation and Coping (SPOC) questionnaire is a valid measurement of illness beliefs and predictive of long-term functional recovery prognosis $^{9}$. Patients with high SPOC questionnaire scores following fracture surgery suffer from persistent pain and reduced quality of life ${ }^{49}$.

Cognitive behavioural therapy (CBT), consists of identifying and replacing maladaptive thoughts, emotions, and behaviours with adaptive ones, has been shown to improve selfefficacy and the effects of physical therapy following musculoskeletal ${ }^{50,54,55}$.

Meta-analysis of music therapy demonstrates decreased anxiety, better sleep, and positive effects on pain relief and opioid dose reduction in the setting of chronic medical illness. ${ }^{56}$ Similarly, systematic reviews of aromatherapy have demonstrated anxiolytic effects ${ }^{57}$ and pain reduction ${ }^{58}$. Further research is necessary to identify which patients may benefit from psychosocial interventions, the optimal amount and timing, and the training required to implement the interventions ${ }^{47,50}$.

\section{MANAGING SPECIAL POPULATION}

\section{Geriatric Population}

Orthogeriatric management of patients with hip fracture proved to be effective on frail populations and has already been adopted in many hospitals ${ }^{59,60}$. Zelzter et al., showed a $2.2 \%$ reduction of 30-day mortality in patients admitted to hospitals with orthogeriatric services compared to hospitals without orthogeriatric services ${ }^{61}$.

Exemplified by stroke rehabilitation (which is the most common case of elders in need of rehabilitation), seven main aspects in recommended regimen of geriatric rehabilitation include: 1) therapy time, 2) group training, 3) patient-regulated exercise, 4) family participation, 5) task-oriented training, 6) enriched environment, and 7) team dynamics ${ }^{62}$.

It is agreed that low level of activity is best, while carried out in a prolonged therapy time for better rehabilitation outcomes. Group training and patient-regulated exercise are also preferred to provide motivations, increasing confidence, and enabling increased practice time without increasing staffing ${ }^{63}$. Another important aspect is family participation and the availability of a caregiver at home. It is crucial for the caregiver to participate in the rehabilitation process, which helps prepare them for when the spouse/relative returns home ${ }^{64}$. Additional practice with caregivers led to an increased amount of time spent in exercise which, in turn, led to an improvement in body function, more activities, and better participation ${ }^{65,66}$. 
Task-oriented training create opportunities to practice meaningful functional tasks outside of regular therapy sessions ${ }^{62}$. Creating an enriched environment (with the provision of music, audio books, games, other recreational activities) increase opportunities for practice and promote active engagement ${ }^{67}$. Lastly, since rehabilitation is a team effort, multidisciplinary dynamics is preferred while maintaining shared goals and effective communication ${ }^{68,69}$.

\section{Paediatric Population}

Paediatric populations require special considerations in rehabilitation ${ }^{70}$. The paediatric population is full of young, developing, and eager individuals who want to return to their everyday activities as soon as possible especially following surgery, ${ }^{71}$. Therefore, the main goal to restore function as well as possible and as quickly as possible.

\section{Enhanced Recovery After Surgery} (ERAS) program, consists of minimizing the consequences of surgical stress by controlling pain and stimulating autonomy; informing and educating the patient concerning the process; and planning care organization and discharge is preferred. The expected consequences are: fewer postoperative complications and shorter hospital stay ${ }^{72}$.

The aspects that are needed to be taken into account include patient's age and the parent- child relationship. Care-providers need to be aware of and able to manage the functioning of the parent-child duo. The needs of both child and parent have to be examined. The process consists in transferring skills from parent to child. Obviously, the child also needs to have a certain level of understanding (the "age of reason") to be able to follow an education programming the ERAS context. For the parents, there is no child age limit, as they can stand in and accompany their child as he or she progresses ${ }^{72}$.

Lessons should be drawn from existing paediatric therapeutic education programs, to adapt information and training to the child's cognitive, motor and psycho-affective development ${ }^{72}$.

\section{CONCLUSION}

Rehabilitation following musculoskeletal injury and prevention of complication comprise of multifaceted approach. It should not be performed carelessly and initiated without taking aspects such as wound tissue healing into considerations. The key principles must be applied at all times. Apart from usual, evidence-based regimens, holistic alternative-based medicine such as acupuncture and meditation should be taken into account. Both physical and psychological wellbeing should be ensured, and special population such as geriatric and paediatric should receive special care.

\section{References}

1. Tedesco, D., Gibertoni, D., Rucci, P., Hernandez-Boussard, T., Rosa, S., Bianciardi, L., Rolli, M., \& Fantini, M. $P$. (2018). Impact of rehabilitation on mortality and readmissions after surgery for hip fracture. BMC health services research, 18(1), 701. https://doi.org/10.1186/s12913-018-3523-x.

2. Ireland, A. W., Kelly, P. J., \& Cumming, R. G. (2016). Associations between hospital-based rehabilitation for hip fracture and two-year outcomes for mortality and independent living: An Australian database study of 1,724 elderly community-dwelling patients. Journal of rehabilitation medicine, 48(7), 625-631. 
https://doi.org/10.2340/16501977-2108.

3. Wilk, K. E., \& Arrigo, C. A. (2018). Rehabilitation: Common Problems and Solutions. Clinics in sports medicine, 37(2), 363-374. https://doi.org/10.1016/j.csm.2017.12.010.

4. Ma, R., Brimmo, O. A., Li, X., \& Colbert, L. (2017). Current Concepts in Rehabilitation for Traumatic Anterior Shoulder Instability. Current reviews in musculoskeletal medicine, 10(4), $499-506$. https://doi.org/10.1007/s12178-017-9449-9.

5. Koukourikos, K., Tsaloglidou, A., \& Kourkouta, L. (2014). Muscle atrophy in intensive care unit patients. Acta informatica medica : AIM : journal of the Society for Medical Informatics of Bosnia \& Herzegovina : casopis Drustva za medicinsku informatiku BiH, 22(6), 406-410. https://doi.org/10.5455/aim.2014.22.406-410.

6. Kearney RS, McKeown R, Stevens S, et al. (2018). Cast versus functional brace in the rehabilitation of patients treated for an ankle fracture: protocol for the UK study of ankle injury rehabilitation (AIR) multicentre randomised trial. BMJ Open 8:e027242. doi: 10.1136/bmjopen-2018-027242.

7. George W. (2013). General Principles of Fracture Treatment. In: Canale ST, Beaty JH, editors. Campbell's Operative Orthopaedic. 12th ed. Philadelphia: Elsevier. p. 2608.

8. Greising, S. M., Corona, B. T., \& Call, J. A. (2020). Musculoskeletal Regeneration, Rehabilitation, and Plasticity Following Traumatic Injury. International journal of sports medicine, 41(8), 495-504. https://doi.org/10.1055/a1128-7128.

9. You, D. Z., Leighton, J. L., \& Schneider, P. S. (2020). Current Concepts in Rehabilitation Protocols to Optimize Patient Function Following Musculoskeletal Trauma. Injury, 51 Suppl 2, S5-S9. https://doi.org/10.1016/j.injury.2020.03.047.

10. Bach, J. A., Leskovan, J. J., Scharschmidt, T., Boulger, C., Papadimos, T. J., Russell, S., Bahner, D. P., \& Stawicki, S. P. (2017). The right team at the right time - Multidisciplinary approach to multi-trauma patient with orthopedic injuries. International journal of critical illness and injury science, 7(1), 32-37. https://doi.org/10.4103/IJCIIS.IJCIIS_5_17.

11. Stinner D. J. (2016). Improving Outcomes Following Extremity Trauma: The Need for a Multidisciplinary Approach. Military medicine, 181(S4), 26-29. https://doi.org/10.7205/MILMED-D-15-00511.

12. Fan, L., \& Arraf, J. (2017). Postoperative management: general considerations. In R. E. Buckley, C. G. Moran, \& T. Apivatthakakul, AO Principles of Fracture Management (3rd ed., Vol. 4, pp. 437-449). India: Thieme Medical and Scientific Publishers.

13. Hoogervorst, P., Shearer, D. W., \& Miclau, T. (2020). The Burden of High-Energy Musculoskeletal Trauma in High-Income Countries. World journal of surgery, 44(4), 1033-1038. https://doi.org/10.1007/s00268-018-47423.

14. Buckenmaier C. C., 3rd (2012). The role of pain management in recovery following trauma and orthopaedic surgery. The Journal of the American Academy of Orthopaedic Surgeons, 20 Suppl 1, S35-S38. https://doi.org/10.5435/JAAOS-20-08-S35.

15. Rosenbloom, B. N., Katz, J., Chin, K. Y., Haslam, L., Canzian, S., Kreder, H. J., \& McCartney, C. J. (2016). Predicting pain outcomes after traumatic musculoskeletal injury. Pain, 157(8), 1733-1743. https://doi.org/10.1097/j.pain.0000000000000580

16. Hsu, J. R., Mir, H., Wally, M. K., Seymour, R. B., \& Orthopaedic Trauma Association Musculoskeletal Pain Task Force (2019). Clinical Practice Guidelines for Pain Management in Acute Musculoskeletal Injury. Journal of orthopaedic trauma, 33(5), e158-e182. https://doi.org/10.1097/BOT.0000000000001430

17. Dart, R. C., Surratt, H. L., Cicero, T. J., Parrino, M. W., Severtson, S. G., Bucher-Bartelson, B., \& Green, J. L. (2015). Trends in opioid analgesic abuse and mortality in the United States. The New England journal of medicine, 372(3), 241-248. https://doi.org/10.1056/NEJMsa1406143

18. Carnide, N., Hogg-Johnson, S., Côté, P., Irvin, E., Van Eerd, D., Koehoorn, M., \& Furlan, A. D. (2017). Early Prescription Opioid Use for Musculoskeletal Disorders and Work Outcomes: A Systematic Review of the Literature. The Clinical journal of pain, 33(7), 647-658. https://doi.org/10.1097/AJP.0000000000000452.

19. Chang AK, Bijur PE, Esses D, Barnaby DP, Baer J. Effect of a Single Dose of Oral Opioid and Nonopioid Analgesics on Acute Extremity Pain in the Emergency Department: A Randomized Clinical Trial. JAMA. 2017 Nov 7;318(17):1661-1667. doi: 10.1001/jama.2017.16190. PMID: 29114833; PMCID: PMC5818795.

20. Alexander, R., El-Moalem, H. E., \& Gan, T. J. (2002). Comparison of the morphine-sparing effects of diclofenac sodium and ketorolac tromethamine after major orthopedic surgery. Journal of clinical anesthesia, 14(3), 187192. https://doi.org/10.1016/s0952-8180(01)00382-8

21. Gordon, W. T., Stannard, J. P., Pasquina, P. F., Archer, K. R., \& Extremity War Injuries VII Rehabilitation Panel (2012). Evolution of orthopaedic rehabilitation care. The Journal of the American Academy of Orthopaedic Surgeons, 20 Suppl 1, S80-S83. https://doi.org/10.5435/JAAOS-20-08-S80.

22. Yang, J., Bauer, B. A., Wahner-Roedler, D. L., Chon, T. Y., \& Xiao, L. (2020). The Modified WHO Analgesic Ladder: Is It Appropriate for Chronic Non-Cancer Pain?. Journal of pain research, 13, 411-417. https://doi.org/10.2147/JPR.S244173

23. Madsen, C., Vaughan, M., \& Koehlmoos, T. P. (2017). Use of Integrative Medicine in the United States Military Health System. Evidence-based complementary and alternative medicine : eCAM, 2017, 9529257. https://doi.org/10.1155/2017/9529257 
24. Stanos S. P. (2017). Stemming the Tide of the Pain and Opioid Crisis: AAPM Reaffirms Its Commitment to Multidisciplinary Biopsychosocial Care and Training. Pain medicine (Malden, Mass.), 18(6), 1005-1006. https://doi.org/10.1093/pm/pnx120

25. Chou, R., Gordon, D. B., de Leon-Casasola, O. A., Rosenberg, J. M., Bickler, S., Brennan, T., Carter, T., Cassidy, C. L., Chittenden, E. H., Degenhardt, E., Griffith, S., Manworren, R., McCarberg, B., Montgomery, R., Murphy, J., Perkal, M. F., Suresh, S., Sluka, K., Strassels, S., Thirlby, R., ... Wu, C. L. (2016). Management of Postoperative Pain: A Clinical Practice Guideline From the American Pain Society, the American Society of Regional Anesthesia and Pain Medicine, and the American Society of Anesthesiologists' Committee on Regional Anesthesia, Executive Committee, and Administrative Council. The journal of pain, 17(2), $131-157$. https://doi.org/10.1016/j.jpain.2015.12.008

26. Yun, H. C., Murray, C. K., Nelson, K. J., \& Bosse, M. J. (2016). Infection After Orthopaedic Trauma: Prevention and Treatment. Journal of orthopaedic trauma, 30 Suppl 3, S21-S26. https://doi.org/10.1097/BOT.0000000000000667

27. Rajasekaran S, Devendra A, Perumal R, Dheenadhayalan J, Sundararajan SR. (2015). Initial Management of Open Fractures. In: McKee MD, editor. Rockwood and Green's Fractures in Adults. 8th ed. p. 353-93

28. Lingaraj, R., Santoshi, J. A., Devi, S., Najimudeen, S., Gnanadoss, J. J., Kanagasabai, R., \& Kanungo, R. (2015). Predebridement wound culture in open fractures does not predict postoperative wound infection: A pilot study. Journal of natural science, biology, and medicine, 6(Suppl 1), S63-S68. https://doi.org/10.4103/09769668.166088

29. Zavascki, A. P., Bulitta, J. B., \& Landersdorfer, C. B. (2013). Combination therapy for carbapenem-resistant Gram-negative bacteria. Expert review of anti-infective therapy, 11(12), 1333-1353.

30. Ali, A. M., Noyes, D., \& Cogswell, L. K. (2013). Management of open fractures of the lower limb. British journal of hospital medicine (London, England : 2005), 74(10), 577-580.

31. Carver, D. C., Kuehn, S. B., \& Weinlein, J. C. (2017). Role of Systemic and Local Antibiotics in the Treatment of Open Fractures. Orthopedic Clinics of North America, 48(2), 137-153. doi:10.1016/j.ocl.2016.12.005

32. Brown, K. V., Walker, J. A., Cortez, D. S., Murray, C. K., \& Wenke, J. C. (2010). Earlier debridement and antibiotic administration decrease infection. Journal of surgical orthopaedic advances, 19(1), 18-22.

33. Hoff, W. S., Bonadies, J. A., Cachecho, R., \& Dorlac, W. C. (2011). East Practice Management Guidelines Work Group: update to practice management guidelines for prophylactic antibiotic use in open fractures. The Journal of trauma, 70(3), 751-754.

34. Penn-Barwell, J. G., Murray, C. K., \& Wenke, J. C. (2012). Early antibiotics and debridement independently reduce infection in an open fracture model. The Journal of bone and joint surgery. British volume, 94(1), 107112. https://doi.org/10.1302/0301-620X.94B1.27026

35. Glass, G. E., Barrett, S. P., Sanderson, F., Pearse, M. F., \& Nanchahal, J. (2011). The microbiological basis for a revised antibiotic regimen in high-energy tibial fractures: preventing deep infections by nosocomial organisms. Journal of plastic, reconstructive \& aesthetic surgery : JPRAS, 64(3), 375-380. https://doi.org/10.1016/j.bjps.2010.05.037

36. Murray O, Macdonald D, Nunn T, McEachan J and Rymaszewski L. (2012) Management of the post-traumatic stiff elbow. Journal of Shoulder and Elbow Surgery (4): p38-45.

37. Jones V. (2016). Conservative management of the post-traumatic stiff elbow: a physiotherapist's perspective. Shoulder \& elbow, 8(2), 134-141. https://doi.org/10.1177/1758573216633065

38. Barrett C. (2015). The clinical physiotherapy assessment of non-traumatic shoulder instability. Shoulder \& elbow, 7(1), 60-71. https://doi.org/10.1177/1758573214548934

39. Giannicola, G., Polimanti, D., Bullitta, G., Sacchetti, F. M., \& Cinotti, G. (2014). Critical time period for recovery of functional range of motion after surgical treatment of complex elbow instability: prospective study on 76 patients. Injury, 45(3), 540-545.

40. Macdermid, J. C., Vincent, J. I., Kieffer, L., Kieffer, A., Demaiter, J., \& Macintosh, S. (2012). A survey of practice patterns for rehabilitation post elbow fracture. The open orthopaedics journal, 6, 429-439.

41. Mulligan BR. Mobilisations with movement (MWMs). J Man Manip Ther 1993; 1: 154-6.

42. Page P. (2012). Current concepts in muscle stretching for exercise and rehabilitation. International journal of sports physical therapy, 7(1), 109-119.

43. Kristensen, J., \& Franklyn-Miller, A. (2012). Resistance training in musculoskeletal rehabilitation: a systematic review. British journal of sports medicine, 46(10), 719-726. https://doi.org/10.1136/bjsm.2010.079376

44. Jackson, J. K., Shepherd, T. R., \& Kell, R. T. (2011). The influence of periodized resistance training on recreationally active males with chronic nonspecific low back pain. Journal of strength and conditioning research, 25(1), 242-251. https://doi.org/10.1519/JSC.0b013e3181b2c83d

45. Menta, R., Randhawa, K., Côté, P., Wong, J. J., Yu, H., Sutton, D., Varatharajan, S., Southerst, D., D'Angelo, K., Cox, J., Brown, C., Dion, S., Mior, S., Stupar, M., Shearer, H. M., Lindsay, G. M., Jacobs, C., \& TaylorVaisey, A. (2015). The effectiveness of exercise for the management of musculoskeletal disorders and injuries of the elbow, forearm, wrist, and hand: a systematic review by the Ontario Protocol for Traffic Injury Management (OPTIMa) collaboration. Journal of manipulative and physiological therapeutics, 38(7), 507-520.

46. Cullinane, F. L., Boocock, M. G., \& Trevelyan, F. C. (2014). Is eccentric exercise an effective treatment for 
lateral epicondylitis? A systematic review. Clinical rehabilitation, 28(1), 3-19. https://doi.org/10.1177/0269215513491974

47. Haupt E, Vincent HK, Harris A, Vasilopoulos T, Guenther R, Sharififar S. (2018) Pre-injury depression and anxiety in patients with orthopedic trauma and their treatment. Journal of Injury (49):1079-84. doi: 10.1016/j.injury.2018.03.024 .

48. Vincent HK, Vasilopoulos T, Zdziarski-Horodyski LA, Sadasivan KK, Hagen J, Guenther R, et al. (2018). Preexisting psychiatric illness worsens acute care outcomes after orthopaedic trauma in obese patients. Journal of Injury (49):243-8. doi: 10.1016/ j.injury.2017.12.004 .

49. Busse JW, Heels-Ansdell D, Makosso-Kallyth S, Petrisor B, Jeray K, Tufescu T, et al. (2019). Patient coping and expectations predict recovery after major orthopaedic trauma. British Journal of Anaesthesia (122):51-9. doi: 10.1016/j.bja.2018.06.021.

50. Bostick G. P. (2017). Effectiveness of psychological interventions delivered by non-psychologists on low back pain and disability: a qualitative systematic review. The spine journal : official journal of the North American Spine Society, 17(11), 1722-1728.

51. Beaupre, L. A., Binder, E. F., Cameron, I. D., Jones, C. A., Orwig, D., Sherrington, C., \& Magaziner, J. (2013). Maximising functional recovery following hip fracture in frail seniors. Best practice \& research. Clinical rheumatology, 27(6), 771-788.

52. Morghen, S., Bellelli, G., Manuele, S., Guerini, F., Frisoni, G. B., \& Trabucchi, M. (2011). Moderate to severe depressive symptoms and rehabilitation outcome in older adults with hip fracture. International journal of geriatric psychiatry, 26(11), 1136-1143. https://doi.org/10.1002/gps.2651.

53. Flanigan, D. C., Everhart, J. S., \& Glassman, A. H. (2015). Psychological Factors Affecting Rehabilitation and Outcomes Following Elective Orthopaedic Surgery. The Journal of the American Academy of Orthopaedic Surgeons, 23(9), 563-570. https://doi.org/10.5435/JAAOS-D-14-00225

54. Archer, K. R., Abraham, C. M., \& Obremskey, W. T. (2015). Psychosocial Factors Predict Pain and Physical Health After Lower Extremity Trauma. Clinical orthopaedics and related research, 473(11), 3519-3526. https://doi.org/10.1007/s11999-015-4504-6

55. Walsh, M. V., Armstrong, T. W., Poritz, J., Elliott, T. R., Jackson, W. T., \& Ryan, T. (2016). Resilience, Pain Interference, and Upper Limb Loss: Testing the Mediating Effects of Positive Emotion and Activity Restriction on Distress. Archives of physical medicine and rehabilitation, 97(5), $781-787$. https://doi.org/10.1016/j.apmr.2016.01.016

56. Bradt, J., Dileo, C., \& Potvin, N. (2013). Music for stress and anxiety reduction in coronary heart disease patients. The Cochrane database of systematic reviews, (12), CD006577. https://doi.org/10.1002/14651858.CD006577.pub3.

57. Lee, Y. L., Wu, Y., Tsang, H. W., Leung, A. Y., \& Cheung, W. M. (2011). A systematic review on the anxiolytic effects of aromatherapy in people with anxiety symptoms. Journal of alternative and complementary medicine (New York, N.Y.), 17(2), 101-108.

58. Lakhan SE, Sheafer H, Tepper D. (2016) The effectiveness of aromatherapy in reducing pain: a systematic review and meta-analysis. Journal of Pain Research and Treatment. 2016:8158693.

59. Lahtinen, A., Leppilahti, J., Harmainen, S., Sipilä, J., Antikainen, R., Seppänen, M. L., Willig, R., Vähänikkilä, H., Ristiniemi, J., Rissanen, P., \& Jalovaara, P. (2015). Geriatric and physically oriented rehabilitation improves the ability of independent living and physical rehabilitation reduces mortality: a randomised comparison of 538 patients. Clinical rehabilitation, 29(9), 892-906. https://doi.org/10.1177/0269215514559423.

60. Gosch, M., Hoffmann-Weltin, Y., Roth, T., Blauth, M., Nicholas, J. A., \& Kammerlander, C. (2016). Orthogeriatric co-management improves the outcome of long-term care residents with fragility fractures. Archives of orthopaedic and trauma surgery, 136(10), 1403-1409. https://doi.org/10.1007/s00402-016-25434.

61. Zeltzer, J., Mitchell, R. J., Toson, B., Harris, I. A., Ahmad, L., \& Close, J. (2014). Orthogeriatric services associated with lower 30-day mortality for older patients who undergo surgery for hip fracture. The Medical journal of Australia, 201(7), 409-411. https://doi.org/10.5694/mja14.00055.

62. Tijsen, L. M., Derksen, E. W., Achterberg, W. P., \& Buijck, B. I. (2019). Challenging rehabilitation environment for older patients. Clinical interventions in aging, 14, 1451-1460. https://doi.org/10.2147/CIA.S207863

63. English, C., Hillier, S. L., \& Lynch, E. A. (2017). Circuit class therapy for improving mobility after stroke. The Cochrane database of systematic reviews, 6(6), CD007513. https://doi.org/10.1002/14651858.CD007513.pub3

64. Galvin, R., Cusack, T., O'Grady, E., Murphy, T. B., \& Stokes, E. (2011). Family-mediated exercise intervention (FAME): evaluation of a novel form of exercise delivery after stroke. Stroke, 42(3), 681-686. https://doi.org/10.1161/STROKEAHA.110.594689

65. Vloothuis, J. D., Mulder, M., Veerbeek, J. M., Konijnenbelt, M., Visser-Meily, J. M., Ket, J. C., Kwakkel, G., \& van Wegen, E. E. (2016). Caregiver-mediated exercises for improving outcomes after stroke. The Cochrane database of systematic reviews, 12(12), CD011058. https://doi.org/10.1002/14651858.CD011058.pub2

66. Tanwir, S., Montgomery, K., Chari, V., \& Nesathurai, S. (2014). Stroke rehabilitation: availability of a family member as caregiver and discharge destination. European journal of physical and rehabilitation medicine, 
50(3), 355-362.

67. Eng, X. W., Brauer, S. G., Kuys, S. S., Lord, M., \& Hayward, K. S. (2014). Factors Affecting the Ability of the Stroke Survivor to Drive Their Own Recovery outside of Therapy during Inpatient Stroke Rehabilitation. Stroke research and treatment, 2014, 626538. https://doi.org/10.1155/2014/626538

68. Karol R. L. (2014). Team models in neurorehabilitation: structure, function, and culture change. NeuroRehabilitation, 34(4), 655-669. https://doi.org/10.3233/NRE-141080

69. Jesus, T. S., \& Hoenig, H. (2015). Postacute rehabilitation quality of care: toward a shared conceptual framework. Archives of physical medicine and rehabilitation, 96(5), 960-969. https://doi.org/10.1016/j.apmr.2014.12.007

70. Kolman, S., Spiegel, D., Namdari, S., Hosalkar, H., Keenan, M. A., \& Baldwin, K. (2015). What's New in Orthopaedic Rehabilitation. The Journal of bone and joint surgery. American volume, 97(22), 1892-1898. https://doi.org/10.2106/JBJS.0.00827.

71. Sarkisova, N., Smith, R., VandenBerg, C., Pace, J. L., \& Goldstein, R. Y. (2019). Access to Physical Therapy for Pediatric and Adolescent Patients Following Orthopedic Surgery. Global pediatric health, 6, 2333794X19848676. https://doi.org/10.1177/2333794X19848676

72. Garin C. (2020). Enhanced recovery after surgery in pediatric orthopedics (ERAS-PO). Orthopaedics \& traumatology, surgery \& research : OTSR, 106(1S), S101-S107. https://doi.org/10.1016/j.otsr.2019.05.012 